\title{
The Cumulative Effect of Hyperactivity and Peer Relationships on Reading Comprehension
}

\author{
Kaprea F Johnson ${ }^{1}$ \\ ${ }^{1}$ College of Education, Old Dominion University, Norfolk VA, USA \\ Correspondence: Dr. Kaprea F Johnson, 110 Education Building, Counseling and Human Services Department, \\ Old Dominion University, Norfolk, VA 23529, USA.
}

Received: September 18, 2013 Accepted: October 3, 2013 Online Published: October 21, 2013

doi:10.11114/jets.v2i1.245 URL: http://dx.doi.org/10.11114/jets.v2i1.245

\begin{abstract}
The impact of hyperactivity and peer relationships on academic achievement has long been highlighted in the professional literature. This study highlights how much variation in reading comprehension scores, an indicator of academic achievement, are accounted for by hyperactivity, conduct problems, and peer problems. The participants included 129 students in first through sixth grade in an urban school district in the Northeast. A multiple regression analysis was used to investigate the unique contributions of hyperactivity, peer relationships, and conduct problems on reading comprehension. Results indicated that increasing levels of peer problems were associated with decreasing reading comprehension scores.
\end{abstract}

Keywords: Hyperactivity, peer relationships, reading comprehension

\section{Introduction}

The importance of peer relationships on academic success has long been investigated in the research literature in counseling, teacher education, and psychology. In recent years, studies have found independently that hyperactivity has an inverse relationship with positive peer relationships and reading comprehension. Likewise, negative peer relationships have been linked to poor academic achievement. The following study seeks to determine the cumulative effect of hyperactivity and peer relationships on an indicator of academic achievement, reading comprehension.

The ability to read and comprehend is a major milestone in a child's life and has long standing effects throughout the lifespan. Hence, the multitude of studies that investigate what contributes to poor, delayed, or stagnate reading abilities. This particular investigation focuses on problems with attention and reading ability because of the increased number of children and youth diagnosed with some form of attention deficit.

Children with identifiable levels of hyperactivity are sometimes reported as displaying poor social adjustment or additional externalizing problem behaviors. A longitudinal study which assessed 200 children at age ten, thirteen, seventeen, and twenty seven found that during middle childhood the children rated as having high levels of inattentiveness and hyperactivity were also rated as poor readers with more behavior problems (Willcutt \& Pennington, 2000). Other studies have found a link between students who fit the criteria for ADHD and reading disabilities (Ghelani et al., 2004; Purvis \& Tannock, 1997) and or behavior problems (Maughan et al., 1996). Maughan et al. (1996) focused on reading problems and antisocial behavior in twins. The study found that adolescents who scored in the range of reading disabilities were also more likely to have the indicators for oppositional defiant disorder (ODD) and conduct disorder (CD).

A longitudinal study utilized teacher rated hyperactivity and reading ability in a group of children starting at the age of five until they reached twenty-six (McGee et al., 2002). The study utilized multiple measures with the most significant being the teacher report of the Child Scale B (Rutter, Tizard, \& Whitmore, 1970) and children used the World Knowledge Test of the ACER Primary Reading Survey Test (Australian Council for Educational Research, 1972; Prior, Sanson, Smart, \& Oberklaid, 1995). When hyperactivity increased, so did poorer outcomes for reading ability, conduct disorder, juvenile arrest/conviction, substance dependence, attention problems, and leaving school without formal qualifications (McGee et al., 2002). Additional results pointed to linear trends indicating that higher levels of attention problems and poorer reading, increased the likelihood of hyperactivity. The appearance of hyperactivity in young children was also associated with disruptive adolescent behavior. 
Children who have identifiable levels of hyperactivity or inattention tend to have some difficulty with reading comprehension (Ghelani et al., 2004; Velting \& Whitehurst, 1997; Purvis \& Tannock, 1997; Cantwell \& Satter-field, 1978). Further findings allude to a connection between hyperactivity, reading comprehension and peer/conduct problems (McGee et al., 2002; Maughan et al., 1996). Independently has shown an inverse relationship between hyperactivity and reading comprehension (McGee, Prior, Williams, Smart, \& Sanson, 2002; Velting \& Whitehurst, 1997), hyperactivity and conduct problems (McGee et al., 2002), and hyperactivity and peer problems (Rubin \& Clark, 1983; Olson \& Brodfeld, 1991). This study focuses on the cumulative effect of hyperactivity and peer relationships on reading comprehension.

Specific research questions were:

(1) How much variance in reading comprehension scores are accounted for by hyperactivity, conduct problems, and peer problems (i.e. externalizing behaviors)?

(2) How does the level of externalizing behaviors relate to reading comprehension scores?

\section{Method}

\subsection{Participants}

The sample for this study included 129 elementary school students who participated in a free afterschool program in the 2009 -2010 school year in an urban school district in the Northeast. Racially, the group was $81.6 \%$ African American, 17\% Latino, and 1.2\% Asian. Participants were in the following grades at the time of the study: $5.2 \%$ in first grade, $12.3 \%$ were second graders, $21.4 \%$ in third grade, $20.8 \%$ in fourth grade, $28.6 \%$ were fifth graders, and $11.7 \%$ were in sixth grade. Missing data brought the valid $\mathrm{N}$ to 91 .

\subsection{Demographics}

Information was gathered by asking children to report their sex (where $1=$ Males and $2=$ Females), grade, age, and race-ethnicity (where $1=$ African American, $2=$ Hispanic/Latino, $3=$ Other). Participants in the other category frequently described themselves as mixed race or Asian.

\subsection{Strength and Difficulties}

Strength and Difficulties Questionnaire (SDQ; Goodman, Meltzer, Bailey, 1998) is a 25-item (5 subscales) measure assessing conduct problems (e.g. gets very angry), hyperactivity-inattention (e.g. constant fidgeting), emotional symptoms (e.g. nervousness), peer problems (e.g. plays alone), and pro-social behavior (e.g. considerate of others) which can be answered by the youth, parent, or a teacher. According to Goodman (2001) the items are based on concepts from the Diagnostic and Statistical Manual of Mental Disorders $4^{\text {th }}$ edition. Responses are recorded on a 3-point Likert type response scale (2-certainly true, 1-somewhat true, and 0- not true) that assesses agreement that the item describes the child's behavior over the past six months. Negatively worded items are reverse coded. The current study used the peer problems, conduct problems, and hyperactivity student report subscales.

\subsection{Gray Oral Reading Test 4th Ed.}

Gray Oral Reading Test $4^{\text {th }}$ edition (GORT -4 ; Wiederholt, \& Bryant, 2001) is a measure of oral reading comprehension skills which yields a five score oral reading skills in terms of rate, accuracy, fluency, comprehension, and overall reading ability. The current study only used the reading comprehension score. The reliability of the GORT-4 is high with average internal consistency reliabilities above .80 .

\subsection{Procedures}

Children involved in the study were a part of a larger on-going study conducted in after-school programs in the Northeast. Children who participated in the larger on-going program were identified as being at high risk for truancy and school failure through nomination by teachers, clergy, school counselors or principals, and local law enforcement.

In the beginning of the 2009 school year, participants' parents gave informed consent. Participants filled out the self-report measures using paper and pencil during after-school hours with little assistance from staff.

\subsection{Data Analysis}

Multiple regression was used to investigate research question one to determine which independent variable predicted reading comprehension the most. Cross tabulation was used to find the percentage of students in groups defined as low and high based on the total group means for the following variables: hyperactivity, conduct problems, peer problems, and reading comprehension. An independent samples t-test was used to answer research question two, determining if there were meaningful differences in the mean reading scores between groups. 
Additionally, externalizing behaviors were separated into dichotomous groups based on the mean score for the entire sample. Specifically, the mean hyperactivity score for the SDQ hyperactivity subscale was 1.04 . Scores at or below the mean were labeled 'lower hyperactivity' and those above the mean were categorized as 'higher hyperactivity'. Similarly, for conduct problems the mean on the SDQ subscale was .67. Participants at or below the mean were considered to have a lower level of conduct problems and those above the mean were grouped together. The mean for the peer problems SDQ subscale was1.00 and the same procedure was utilized for dichotomous grouping. See table 3 for the number of students in each group.

\section{Results}

In order to facilitate an evaluation of the independent and cumulative effects of hyperactivity, conduct problems, and peer problems, on reading comprehension, multiple regression was used to answer research question one.. Preliminary analyses were conducted and found no violation of the assumptions of normality, linearity, multicollinearity, and homoscedasticity. The model with three independent variables (hyperactivity, conduct problems, and peer problems) explained $9.8 \%$ of the variance in reading comprehension scores (see Table 1), F $(3,80)=2.88, \mathrm{p}=.04$. In the model, peer problems was the only statistically significant variable (beta $=-.309$, $\mathrm{p}<.01)$. Results indicate that the externalizing variables only account for a small amount of the variance in reading comprehension scores; however peer problems accounts for more variance than hyperactivity and conduct problems.

Table 1. Summary of Multiple Regression Analyses for Variables Predicting Reading Comprehension Scores (N=91) Reading Comprehension Scores

\begin{tabular}{llll}
\hline \multicolumn{1}{c}{ Variable } & $B$ & $S E B$ & $\beta$ \\
\hline Hyperactivity & 1.38 & 2.11 & .070 \\
Conduct Problems & -.274 & 2.26 & -.015 \\
Peer Problems & -7.27 & 2.89 & $-.309^{*}$ \\
$\mathrm{R}^{2}$ & & .098 & \\
$\mathrm{~F}$ & & $2.88^{*}$ & \\
\hline
\end{tabular}

Note: $* \mathrm{P}<.05$

Cross tabulation was used to explore the relationship between high and low externalizing behaviors and reading comprehension. Results indicated that the majority of students in the high reading comprehension group were also in the low hyperactivity group (57.9\%), low conduct problems group (65.8\%), and the low peer problems group $(76.3 \%)$. More students were in the low peer problem group and high reading comprehension group than in any other externalizing behavior group.

Table 2. Percentage of Students in High Reading Group Based on Low or High Externalizing Behaviors

\begin{tabular}{lll}
\hline Behavior & Low & High \\
\hline Hyperactivity & $57.9 \%$ & $42.1 \%$ \\
Conduct Problems & $65.8 \%$ & $34.2 \%$ \\
Peer Problems & $76.3 \%$ & $23.7 \%$ \\
\hline
\end{tabular}

Three separate independent samples t-tests were conducted to explore significant differences in reading comprehension scores based on low or high externalizing behavior problems (Table 3). Results indicated that only participants in the low peer problems group had a significantly different score on the reading comprehension assessment (Low peer problems reading comprehension $\mathrm{M}=21.98, \mathrm{sd}=8.35$ and high peer problems reading comprehension $\mathrm{M}=16.64, \mathrm{sd}=10.84 ; \mathrm{t}(82,43.51)=2.49, \mathrm{p}<.01)$. Pearson's product correlation identified a significant inverse relationship between peer problems and reading comprehension as scored by the GORT-4 $(r=$ $-.304, \mathrm{p}<.01)$. Cumulative results indicate that as peer problems decrease reading comprehension increases.

Table 3. Mean scores on reading comprehension based on low or high externalizing behaviors

\begin{tabular}{cccc}
\hline & $N$ & $M(s d)$ & $t$-test \\
\hline Hyperactivity & & & .635 \\
Low & 45 & $20.82(10.68)$ & \\
High & 39 & $19.49(8.08)$ & .377 \\
Conduct Problems & & & \\
Low & 57 & $19.63(8.99)$ & $.249^{* *}$
\end{tabular}




\begin{tabular}{rrr} 
High & 28 & $16.64(10.84)$ \\
\hline Note. $\mathrm{p}<.01^{* * *}$ & &
\end{tabular}

\section{Discussion}

The results of this study indicate the connections between hyperactivity, conduct problems, peer problems on reading comprehension scores. Causality cannot be confirmed, but the results are intriguing. Previous research found the greatest connection between hyperactivity and reading difficulties (McGee, Prior, Williams, \& Smart, Sanson, 2002; Velting \& Whitehurst, 1997; Cantwell \& Satter-field, 1978). When other behavioral variables were included in the research study, findings showed separate inverse relationships for hyperactivity and reading comprehension and behavior problems (McGee et al., 2002). Longitudinal studies have also investigated the relationship between hyperactivity and conduct disorders and then later academic achievement (McGee et al., 2002; Rapport, Scanlan, \& Denney, 1999).The current research study focused on the cumulative effect of self-reported hyperactivity, conduct problems, and peer problems on reading comprehension at one time point.

Contrary to previous research (Frick et al., 1991), the current study found self-report of peer problems was the most significant contribution to reading comprehension scores. Results indicated that as peer problems increase reading comprehension scores decrease. The current study highlights the important role that peers play in academics. Peers are an integral part of healthy development and the status is embodied by a quote from Johnson (1980), "Experiences with peers are not superficial luxuries to be enjoyed by some students and not by others. Student-student relationships are an absolute necessity for healthy cognitive and social development and socialization" (p.125). The interaction between peers is essential in cognitive, social, and behavioral development.

Additional findings from this current research study found that students who were in the high reading group were also in the low externalizing behavior group (low hyperactivity, conduct problems, and peer problems). These findings and prior research further highlight the connection between academic achievement, self-esteem, interpersonal skills, and behavior (Stone \& LaGreca, 1990; Maughan et al., 1996). The relationship between reading comprehension, achievement, and behavior is well documented and has lasting effects on successful adaptation into adulthood (McGee et al., 2002).

\subsection{Limitations}

While the study showed encouraging results, there were several limitations. The small sample size, use of participants from one geographic area, and particular demographics of the population should be taken into account when attempting to generalize the results. It can be noted also that previous studies have been published on the subject matter with fewer study participants (Purvis \& Tannock, 1997). In addition, students in the study were all a part of a larger research study and the sample was not randomly chosen.

\subsection{Conclusion and Future Research}

Future research studies could focus on a larger more geographically diverse population. Longitudinal studies would also provide information on the long-term effects of externalizing behaviors on reading comprehension. Additional research studies can look at further contextual variables affecting reading comprehension, such as, school climate, school connectedness, SES, and self-efficacy.

A surprising finding was the role that peer problems played in reading comprehension scores. Stakeholders in education must be aware of the roles peers play and focus on interventions to build social skills and peer-to-peer interactions. Additionally, prior research on prevention interventions have found success in improving reading comprehension for all youth (Vaugh, Klingner, \& Byant, 2001; Johnson, Rosen, Gupta, Rosen (2013); Gupta, 2004). Additional success has been found with cross-age peer tutoring and teacher led whole class activities to improve reading comprehension (Van Keer, 2004). Collectively, findings from the current study and previous findings would encourage support of peer-to-peer reading interventions, whole school collaborations, and parent-teacher involvement.

\section{References}

American Psychiatric Association. (2000). Diagnostic and statistical manual of mental disorders $\left(4^{\text {th }}\right.$ ed., text rev.). Washington, DC.

Cantwell, D. P., \& Satterfield, J. H. (1978). The prevalence of academic underachievement in hyperactive children. Journal of Pediatric Psychology, 3, 168-171.

Frick, P., Kamphaus, R. W, Lahey, B. B., Loeber, R., Christ, M. G., Hart, E., \& Tannenbaum, L. E. (1991). Academic underachievement and the disruptive behavior disorders. Journal of Consulting and Clinical Psychology, 59, 289-294. 
Ghelani, K., Sidhu, R., Jain, U., \& Tannock, R. (2004). Reading comprehension and reading related abilities in adolescents with reading disabilities and attention-deficit/hyperactivity disorder. Dyslexia, 10, 364-384. http://dx.doi.org/10.1002/dys.285

Gupta, A. (2004). Effects of on-site reading clinical tutoring on children's performance. Reading Matrix, 4, 54-62.

Johnson, D. W. (1980). Group processes: Influences of student-student interaction on school outcomes. In J. H. McMillan (Ed.), Social psychology of school learning (pp. 123-168). New York: Academic Press.

Johnson, K. F., Rosen, H., Gupta, A., \& Rosen H.S. (in press) Improving Reading Comprehension through Holistic Intervening with High Risk Minority Elementary School Students. Mentoring and Tutoring: Partnership in learning.

Maughan, B., Pickles, A., Hagell, A., Rutter, M., \& Yule, W. (1996). Reading problems and antisocial behavior: Developmental trends in comorbidity. Journal Child Psychology and Psychiatry, 37, 405-418. http://dx.doi.org/10.1111/j.1469-7610.1996.tb01421.x

McGee, R., Prior, M., Williams, S., Smart, D., \& Sanson, A. (2002). The long-term significance of teacher-rated hyperactivity and reading ability in childhood: Findings from two longitudinal studies. Journal of Child Psychology and Psychiatry, 43, 1004-1017. http://dx.doi.org/10.1111/1469-7610.00228

McInnes, A., Humphries, T., Hogg-Johnson, S., \& Tannock, R. (2003). Listening comprehension and working memory are impaired in attention-deficit hyperactivity disorder irrespective of language impairment. Journal of Abnormal Child Psychology, 31, 427-444. http://dx.doi.org/10.1023/A:1023895602957

Olson, S., \& Brodfeld, P. L. (1991). Assessment of peer rejection and externalizing behavior problems in preschool boys: A short-term longitudinal study. Journal of Abnormal Child Psychology, 19, 493-503.

Purvis, K. L., \& Tannock, R. (1997). Language abilities in children with attention deficit hyperactivity disorder, reading disabilities, and normal controls. Journal of Abnormal Child Psychology, 25, 133-144. http://dx.doi.org/10.1023/A:1025731529006

Rapport, M. D., Scanlan, S. W., \& Denney, C. B. (1999). Attention-deficit/hyperactivity disorder and scholastic achievement: A model of dual developmental pathways. Journal of Child Psychology and Psychiatry, 40, 1169-1183.

Rubin, K. H., \& Clark, M. L. (1983). Preschool teachers' ratings of behavioral problems: Observational, sociometric, and social cognitive correlates. Journal of Abnormal Child Psychology, 11, 273-86.

Stone, W. L., \& LaGreca, A. M. (1990). The social status of children with learning disabilities: A reexamination. Journal of Learning Disabilities, 23, 32-37.

Van Keer, H. (2004). Fostering reading comprehension in fifth grade by explicit instruction in reading strategies and peer tutoring. British Journal of Educational Psychology, 74, 37-70.

Vaughn, S., Janette, K. Klingner, J. K., \& Bryant, D. P. (2001). Collaborative strategic reading as a means to enhance peer-mediated instruction for reading. Remedial and Special Education, 22, 66-74. http://dx.doi.org/10.1177/074193250102200201

Velting, O. N., \& Whitehurst, G. J. (1997). Inattention-hyperactivity and reading achievement in children from low-income families: A Longitudinal Model. Journal of Abnormal Child Psychology, 25, 321-331. http://dx.doi.org/10.1023/A:1025716520345

Wiederholt, J. L., \& Bryant, B. R. (2001). Gray oral reading test (gort). (4th ed.). Pearson Education.

Willcutt, E. G., \& Pennington, B. F. (2000). Comorbidity of reading disability and attention-deficit/hyperactivity disorder: Differences by gender and subtype. Journal of Learning Disabilities, 33, 179-191. http://dx.doi.org/10.1177/002221940003300206

\section{(cc) EY}

This work is licensed under a Creative Commons Attribution 3.0 License. 